\title{
Formulation, characterization, and in vitro release studies of modified release multiple unit particulate system (MUPS) of venlafaxine hydrochloride
}

\author{
Isaiah BOYAPATI ${ }^{1,2}$ (D), Rajendra AWASTHI $1{ }^{*}$ (D) , Giriraj T. KULKARNI ${ }^{3}$ * (D) \\ 1 Amity Institute of Pharmacy, Amity University Uttar Pradesh, Sector-125, Noida 201313, India. \\ 2 Aurobindo Pharma Ltd., Survey No. 71 \& 72, Indrakaran Village, Kandi (Mandal), Sangareddy District, 502329, \\ Telangana, India. \\ 3 Gokaraju Rangaraju College of Pharmacy, Hyderabad 500090, Telangana, India. \\ * Corresponding Author. E-mail: awasthi02@gmail.com (R.A.); Tel. +91-945-923 45 30, gtkulkarni@gmail.com (G.T.K.); \\ Tel. +91-989-716 6866 .
}

Received: 03 October 2021 / Revised: 09 November 2021 / Accepted: 18 November 2021

\begin{abstract}
Multiple unit particulate system (MUPS) is more recent, challenging, effective and attractive option for the pharmaceutical industries that gives an efficient way to deliver drugs in modified pattern. This study aimed to improve the release profile of venlafaxine hydrochloride by developing modified release MUPS using polyvinyl pyrrolidone K-30, ethyl cellulose $20 \mathrm{cps}$ and Hypromellose E 5LV. Preliminary trials were carried out to select the inert carrier, binder, and viscosity grade of rate controlling polymers. Further, optimization of binder concentration and extended-release coating was carried out. The formulation development of MUPS was divided into two categories as (i) drug layering on inert carrier, i.e., sugar spheres and (ii) extended-release coating. Comparative multimedia dissolution study of venlafaxine hydrochloride extended-release capsules was carried out and compared with the marketed formulation to ascertain the in vitro drug release behavior. XRD study indicated conversion of monohydrate form of venlafaxine hydrochloride and remained unaffected during storage. SEM images confirmed smooth surface of MUPS without any pores. The coated spheres had more dense surface compared to the uncoated pellets. Hypromellose E 5 LV showed better binding properties. Ethyl cellulose $(20 \mathrm{cps})$ showed sustained release profile. The blend containing ER - I spheres (10\% coating) and ER - II spheres (11\% coating) at 60: 40 ratio showed dissolution profile similar to that of the innovator product. The formulated venlafaxine hydrochloride loaded MUPS filled in hard gelatin capsule can open a new avenue for the delivery of therapeutics with improved potential.
\end{abstract}

KEYWORDS: Extended release; multiple unit particulate system; multimedia dissolution; polymorphism; sugar spheres.

\section{INTRODUCTION}

Oral solid dosage forms are the most preferred drug delivery systems due to their ease of administration, easy handling, and cost effectiveness [1]. Oral route provides maximum surface area for drug absorption [2]. Tablets and capsules are the most preferred and well-established pharmaceutical products. Oral drug delivery systems can be broadly classified into immediate release and modified release dosage forms. Immediate release oral dosage forms do not contain any specific polymers to modulate drug release profile and thus allow rapid release the drug after oral administration [3]. A conventional immediate release formulation fails to maintain plasma levels of drug over a prolonged period. These formulations have short duration of action and thus requires multiple daily dosing. This causes fluctuations in drug-plasma level. This is the major limitation associated with immediate release dosage forms. In addition to this, dose missing, and patient compliance are other limitations of immediate release dosage forms.

An ideal dosage form attains desired plasma drug concentration and maintains it for prolonged period [4]. Considering the drawbacks of the immediate release dosage forms, several modified release dosage forms have been developed. A modified-release dosage form improves the drug safety and efficacy due to prolonged and site-specific drug delivery [5, 6]. Modified-release dosage forms can increase drug selectivity and used in the treatment of new indications such as, neuropathic pain to severe or chronic pain management. A modified-

How to cite this article: Boyapati I, Awasthi R, Kulkarni GT. Formulation, characterization, and in vitro release studies of modified release multiple unit particulate system (MUPS) of venlafaxine hydrochloride. J Res Pharm. 2022; 26(1): 75-87. 
release system can protect the drug from degradation in gastric environment and minimize gastric irritation [7]. Modified-release dosage forms are classified as reservoir and matrix systems. A reservoir system follows zero-order kinetics (linear release as a function of time) whereas a matrix system shows a linear release profile as a function of square root of time [8].

Oral polymer-coated modified-release multiple unit particulate system (MUPS) is gaining significant interest of formulation scientist for oral drug delivery applications [9]. MUPS offers advantages, such as higher processing speed, lower cost of processing, rapid processing, and tamper-proof nature of the product in comparision to the conventional capsules and avoid dust problems during compression of conventional tablets. Oral administration of MUPS controls the release of bioactives and thus controls its absorption from the gastrointestinal tract. A MUPS effectively reduces adverse effects while maintaining the plasma level that needed to achieve therapeutic effect for a longer period. Due to the small size, MUPS has uniform and rapid transit in gastrointestinal tract. This reduces localized irritation; improves absorption and bioavailability of drugs. MUPS has various regulatory advantages, such as the extension of patent life and line extension of the product [10]. However, limited products (tablets) for example Antra ${ }^{\circledR}$ MUPS, Prevacid ${ }^{\circledR}$ SoluTab ${ }^{\mathrm{TM}}$ and Beloc $^{\circledR}$ ZOK are available in the market which contains MUPS [11]. Therefore, this is the most flourishing field which needs to focus more on the development of such formulations.

Venlafaxine hydrochloride, freely water-soluble antidepressant molecule, is chemically designated as (R/S) - 1-[2-(dimethylamino)-1-(4-methoxyphenyl) ethyl cyclohexanol hydrochloride [12]. Venlafaxine and its active metabolite O-desmethylvenlafaxine are potent inhibitor of neuronal serotonin and nor-epinephrine reuptake and weak inhibitors of dopamine reuptake [13]. Oral bioavailability of Venlafaxine only $40-45 \%$ due to its extensive first-pass metabolism. Conventional immediate release venlafaxine hydrochloride tablets give

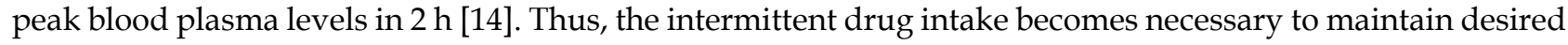
drug concentration at target site. This may lead to the sub or supra therapeutic drug concentrations resulting in unpredicted side effects. Thus, the success of a conventional venlafaxine hydrochloride formulation is limited. Extended-release formulations of Venlafaxine has prolonged absorption profile, resulting in a lower maximum plasma concentration $\left(\mathrm{C}_{\max }\right)$ when compared with that obtained after an immediate-release formulation. Venlafaxine extended-release formulation shows the peak plasma concentrations of Venlafaxine after 5.5 post-dose [15].

The purpose of this study was to improve the release profile of venlafaxine hydrochloride for a prolonged period and to overcome above-mentioned limitations of conventional oral drug delivery systems. To achieve these goals the modified release MUPS was formulated using polyvinyl pyrrolidone K-30, ethyl cellulose $20 \mathrm{cps}$ and Hypromellose E 5LV. Preliminary trials were carried out to select the inert carrier, binder, and viscosity grade of rate controlling polymer. Extended release MUPS was prepared using Hypromellose E $5 \mathrm{LV}$ and ethyl cellulose $20 \mathrm{cps}$. Further, optimization of binder concentration and extended-release coating was carried out. The formulation development of MUPS was divided into two categories as (i) drug layering on inert carrier i.e., sugar spheres and (ii) extended-release coating. Comparative multimedia dissolution study of venlafaxine hydrochloride extended-release capsules was carried out and compared with the marketed formulation to ascertain the in vitro drug release behavior.

\section{RESULTS AND DISCUSSION}

An overlay of the X-ray powder diffraction pattern of venlafaxine hydrochloride (crystalline polymorph form I), venlafaxine hydrochloride monohydrate reference standard, venlafaxine hydrochloride extendedrelease capsules (initial), venlafaxine hydrochloride extended-release capsules (stored at $40 \pm 2{ }^{\circ} \mathrm{C} / 75 \pm 5 \% \mathrm{RH}$ for 3 months) and placebo are presented in Figure 1. X-ray powder diffraction pattern of venlafaxine hydrochloride exhibited a crystalline polymorph form having characteristic intense peaks [16]. The X-ray powder diffraction pattern of venlafaxine hydrochloride extended-release capsules exhibited characteristic peaks of monohydrate form of venlafaxine hydrochloride, indicating the conversion of monohydrate form during formulation, and remained unaffected during storage.

DSC thermogram of pure venlafaxine hydrochloride exhibited an exothermic peak at $218.29^{\circ} \mathrm{C}$ representing its melting point (Figure 2) [17]. Drug loaded pellets containing Hypromellose and ethyl cellulose exhibited exothermic peaks at $215.18^{\circ} \mathrm{C}$ and $215.04^{\circ} \mathrm{C}$, respectively, indicating melting point of the drug. No thermal event in the examined temperature range was observed. Slight decrease in peak area suggesting partial conversion of the crystalline form of the drug to the amorphous state due to loading of the drug within the pellet matrix (Figure 2) [18, 19]. 


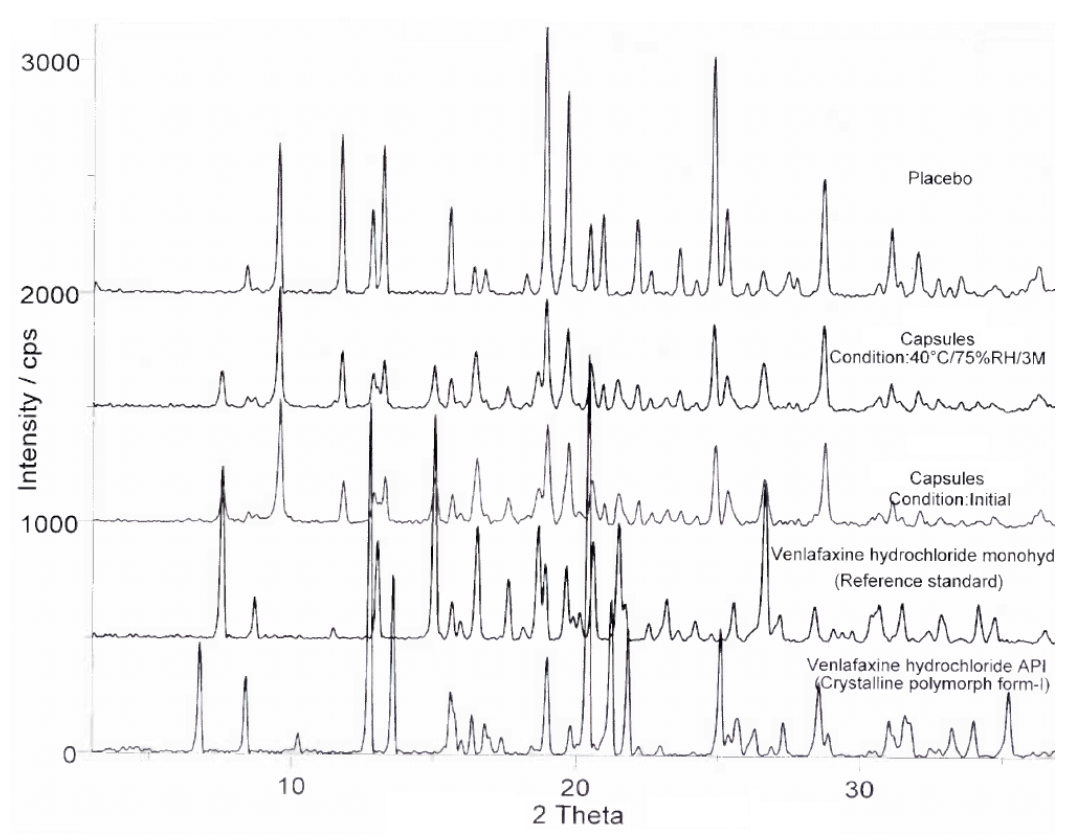

Figure 1. Results of X-ray powder diffraction analysis of venlafaxine hydrochloride API and standard, venlafaxine hydrochloride extended-release capsules (formulation MUPS 1 ) (initial and stored at $40 \pm$ $2^{\circ} \mathrm{C} / 75 \pm 5 \% \mathrm{RH}$ for 3 months) and placebo.
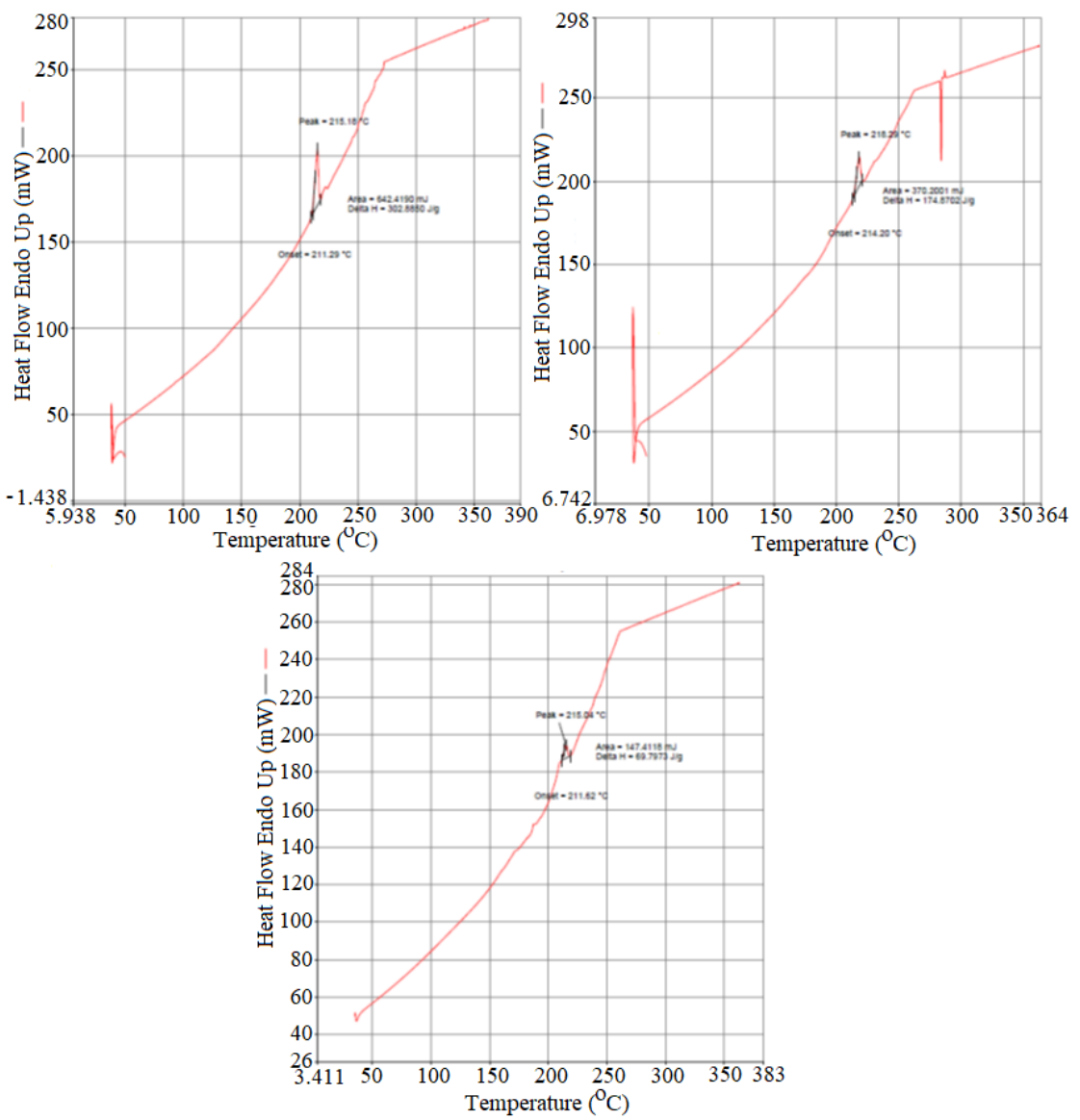

Figure 2. DSC thermogram of pure venlafaxine hydrochloride (A), drug loaded ER-I coated (formulation MUPS $\left._{13}\right)(B)$, and drug loaded ER-II coated micro-pallets (formulation MUPS 16$)(C)$.

Percentage drug loading and optimum amount of the polymer to be used may depends on the particle size. In the present study, more than $90 \%$ of the extended-release Effexor $X{ }^{\circledR}$ spheres were found to pass through \#14 (ASTM $1.4 \mathrm{~mm}$ ) and completely retained on \#25 mesh (Figure 3). Based on the results of size 
distribution study results, it was decided to use sugar spheres in the size range of \# 20 to \#25 to achieve the product with a desired particle range of \#14 pass and \#25 retains.

The results show that the percentage yield of the formulation containing Hypromellose E5LV was higher $(91 \%)$ than the formulation containing polyvinyl pyrrolidone K-30 (86\%). The drug loading of formulation containing Hypromellose E 5LV $(97.8 \%)$ was higher than the formulation containing polyvinyl pyrrolidone K-30 (94.3\%). Higher percentage of drug loading in Hypromellose E5LV containing formulation might be due to the formation of a strong and tight gel consistency. Also, the binder type and binder amount had a strong effect on percentage yield. Thus, Hypromellose E 5LV was selected as binder for further studies.

Initial drug release rate was slow in formulations containing ethyl cellulose 10 and $20 \mathrm{cps}$. However, $57 \%$ of the drug was released from formulation containing ethyl cellulose $10 \mathrm{cps}$ after $6 \mathrm{~h}$ of dissolution study. Only $48 \%$ of drug was released from the formulation containing ethyl cellulose $20 \mathrm{cps}$ in $10 \mathrm{~h}$ (Figure 4). Hence, it was decided to use ethyl cellulose $20 \mathrm{cps}$ to further optimize the percentage of coating required to achieve the desired release profile.

The dissolution profile of none of the particulate system exactly matched to that of the innovator product (Figure 5). It seemed difficult to achieve a comparable dissolution profile using spheres with any single ethyl cellulose USNF: Hypromellose E5 LV ratio. Hence, it was thought worthwhile to use a blend of spheres with different coatings to achieve the required dissolution profile. For this, the dissolution profile of 60: 40 blend of spheres containing 80: 20 and 90: 10 ethyl cellulose USNF: Hypromellose E5 LV coating was carried out.

The dissolution profile of venlafaxine hydrochloride spheres containing ER - I (EC: HPMC) 80:20 and ER - II (EC: HPMC) 90:10 (filled in size ‘0'capsules) matched with that of Effexor ${ }^{\circledR}$ XR capsules $150 \mathrm{mg}$ (Figure 6). Hence, it was decided to blend ER - I and ER - II spheres in the ratio of 60: 40 using talc as lubricant. The spheres formed a loose cohesive mass at low concentration of binder leading to improper fluidization. With higher binder concentration, drug loading efficiency was not improved. Hence, $7 \%$ of the binder was selected as optimum for a satisfactory drug loading efficiency and percentage yield (Table 1).

Table 1. Effect of binder concentration on percentage yield and drug loading.

\begin{tabular}{cccc}
\hline Formulation & MUPS $_{9}$ & MUPS $_{10}$ & MUPS $_{11}$ \\
\hline Yield $(\%)$ & $94.00 \pm 1.83$ & $98.00 \pm 1.91$ & $94.00 \pm 2.34$ \\
Drug loading $(\%)$ & $86.00 \pm 1.05$ & $91.00 \pm 0.97$ & $90.00 \pm 1.33$ \\
\hline
\end{tabular}

To optimize the coating level of ER - I and ER - II, the dissolution study of ER - I and ER - II coated spheres was carried out at 7,10 and $13 \%$ and 8,11 and $14 \%$ coating, respectively. The results show that none of the coating attained the dissolution profile as the innovator product (Figure 7).

The dissolution profile of the blends is presented in Figure $8 \mathrm{~A}$. The dissolution profile of sphere blend containing ER - I spheres with 10\% coating and ER - II spheres with $11 \%$ coating was identical to the innovator product. Hence, a weight buildup of $10 \%$ for ER - I spheres and $11 \%$ for ER - II spheres was finalized. The dissolution profile presented in Figure $8 \mathrm{~B}$ suggest that there is no significant difference between the dissolution profile of capsules containing three ratios of ER - I and ER - II coatings with respect to the innovator product. However, considering the standard deviation values throughout the time points, 60: 40 ratio of blend was finalized and further evaluated to access the comparative multimedia dissolution profiles.

Surface and cross-sectional morphological examination of the drug-loaded sugar pellets before and after ER-I and ER-II coating was carried out using a scanning electron microscope. The pellet surface before and after coatings had relatively smooth surface without any pores (Figure 9). The coated spheres had denser surface compared to the uncoated pellets. Figure 9A shows spherical shape of sugar sphere $(749 \mu \mathrm{m})$ before drug loading and coating with rate controlling polymer. SEM image of cross-section of blank sugar sphere show a surface thickness of $16.2 \mu \mathrm{m}$ (Figure 9B). The size of ER-I coated drug loaded sphere was $1.15 \mathrm{~mm}$ (Figure 9C) with a surface thickness of $19.8 \mu \mathrm{m}$ (Figure 9D). The size of ER-II coated drug loaded sphere was $1.04 \mathrm{~mm}$ (Figure 9E) with a surface thickness of $20.5 \mu \mathrm{m}$ (Figure 9F). In both, the ER-I and ER-II coatings, a clear distinction between the sugar sphere core and a coating layer was recorded with no visible deformation of the coating layer. Even after drug loading and coating of sugar spheres the original spherical shape of the pellets remained unchanged, without visible deformations or damages of the spheres. 


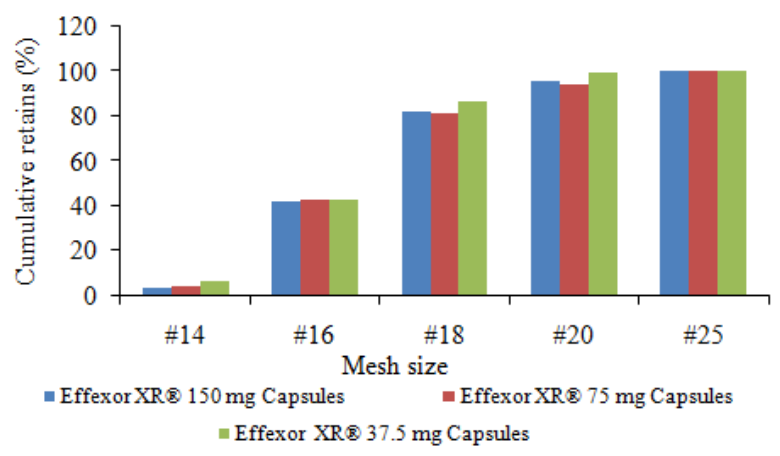

Figure 3. Results of particle size distribution study for the selection of inert carrier (sugar spheres).

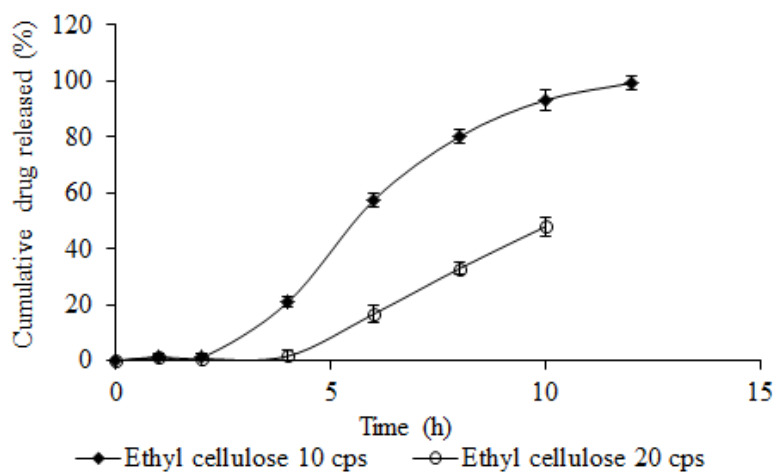

Figure 4. Effect of viscosity grade of rate controlling polymer on dissolution profile of drug in distilled water (filled diamonds: $\mathrm{MUPS}_{3}$ and empty circles: $\mathrm{MUPS}_{4}$ ). Data presents mean $\pm \mathrm{SD}, \mathrm{n}=6$.

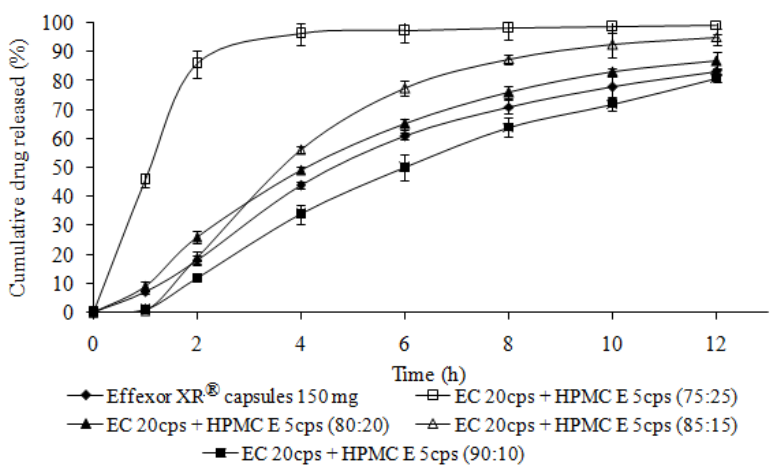

Figure 5. Comparative dissolution profile of venlafaxine hydrochloride from Effector $\mathrm{XR}{ }^{\circledR}$ and extended release MUPS (ethyl cellulose in combination with Hypromellose E 5LV) (Filled diamond: Effexor XR ${ }^{\circledR}$ capsule $150 \mathrm{mg}$, blank squares: $\mathrm{MUPS}_{5}$, filled triangles: $\mathrm{MUPS}_{6}$, empty triangles: $\mathrm{MUPS}_{7}$, filled squares: $\mathrm{MUPS}_{8}$ ) in distilled water. Data presents mean $\pm \mathrm{SD}, \mathrm{n}=6$.

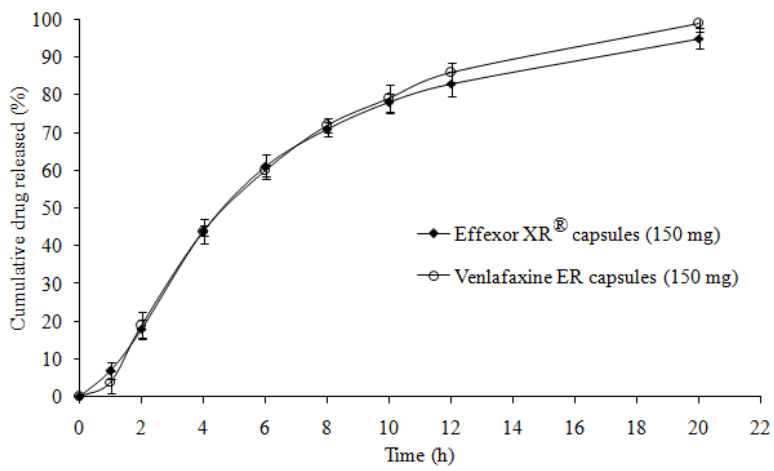

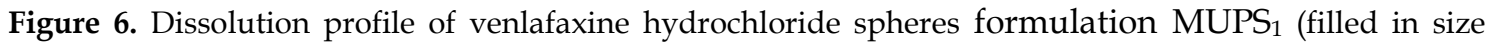
' 0 'capsule) and Effexor ${ }^{\circledR}$ XR capsule in distilled water. Data presents mean $\pm S D, n=6$. 

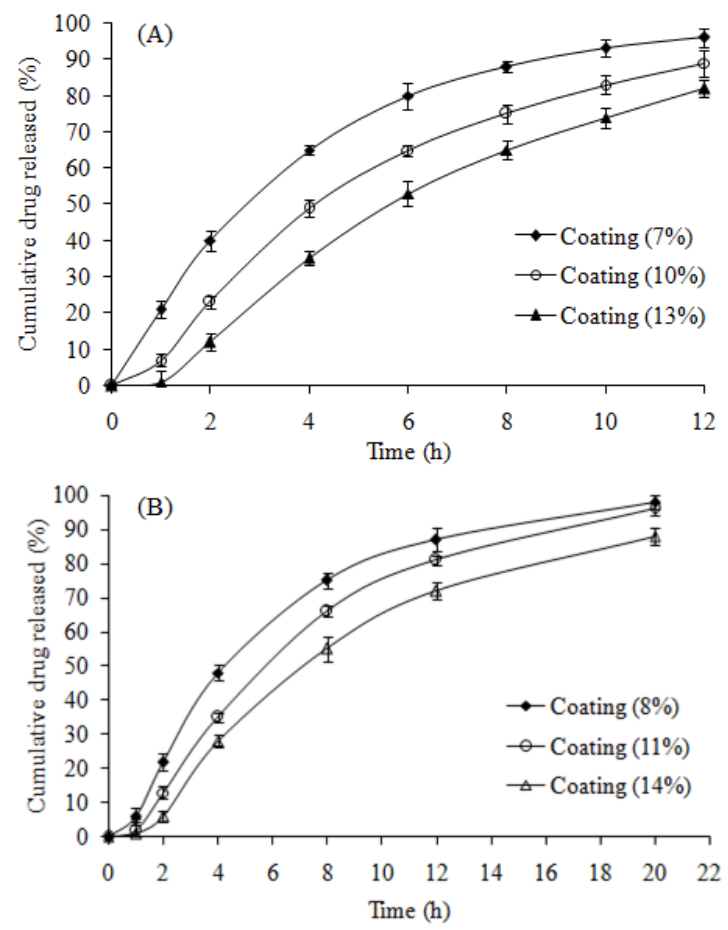

Figure 7. Dissolution profile of venlafaxine hydrochloride from extended-release coating - I (ER - I) (filled diamond $\mathrm{MUPS}_{12}$, empty circle $\mathrm{MUPS}_{13}$, filled triangle $\left.\mathrm{MUPS}_{14}\right)(\mathrm{A})$, and extended-release coating - II (ER II) (filled diamond $\mathrm{MUPS}_{15}$, empty circle $\mathrm{MUPS}_{16}$, empty triangle $\mathrm{MUPS}_{17}$ ) (B) in distilled water. Data presents mean $\pm S D, n=6$.
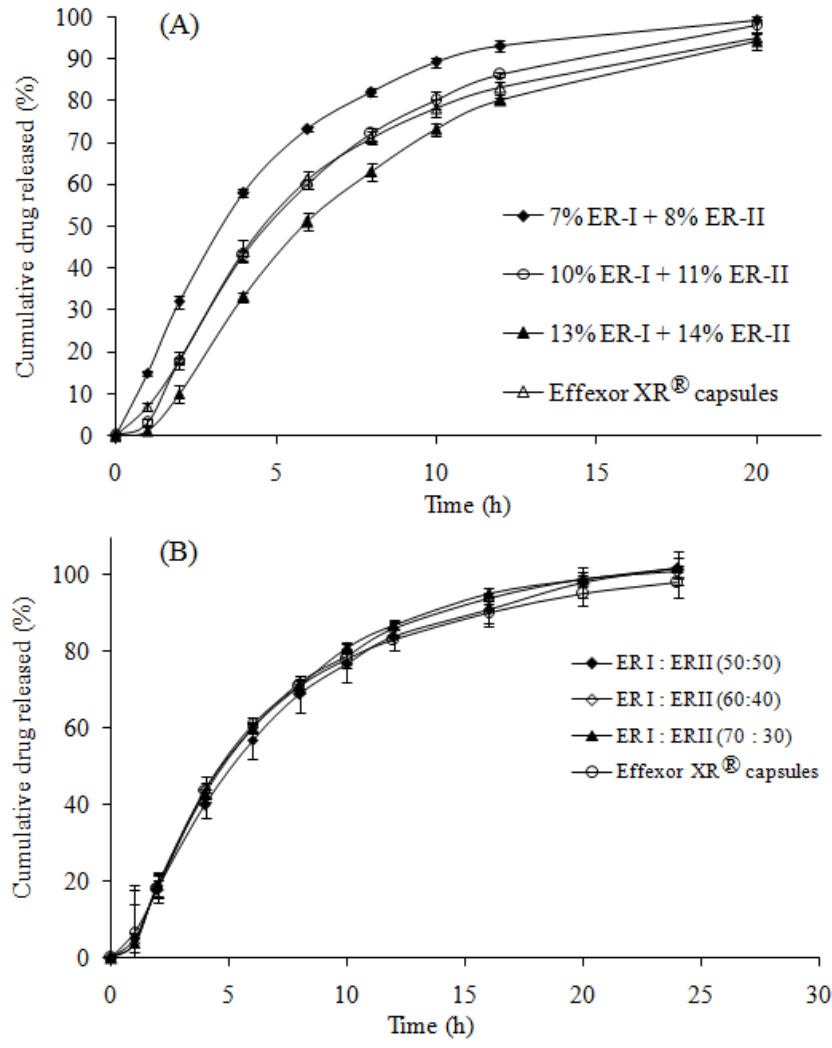

Figure 8. Dissolution profile of venlafaxine hydrochloride from spheres containing blends of ER - I and ER - II ratios (filled diamond: $\mathrm{MUPS}_{12}+\mathrm{MUPS}_{15}$, empty circle: $\mathrm{MUPS}_{13}+\mathrm{MUPS}_{16}$, filled triangle: $\mathrm{MUPS}_{14}+$ MUPS $_{17}$, empty triangle: Effecxor $\mathrm{XR}^{\circledR}$ capsules) (A), and from different ratio of spheres containing blends of ER - I (10\%) and ER - II (11\%) (filled diamond: $\mathrm{MUPS}_{18}$, empty diamond: $\mathrm{MUPS}_{19}$, filled triangle: MUPS 20 , empty circle: Effecxor $X R^{\circledR}$ capsules) (B) in distilled water. Data presents mean $\pm S D, n=6$. 


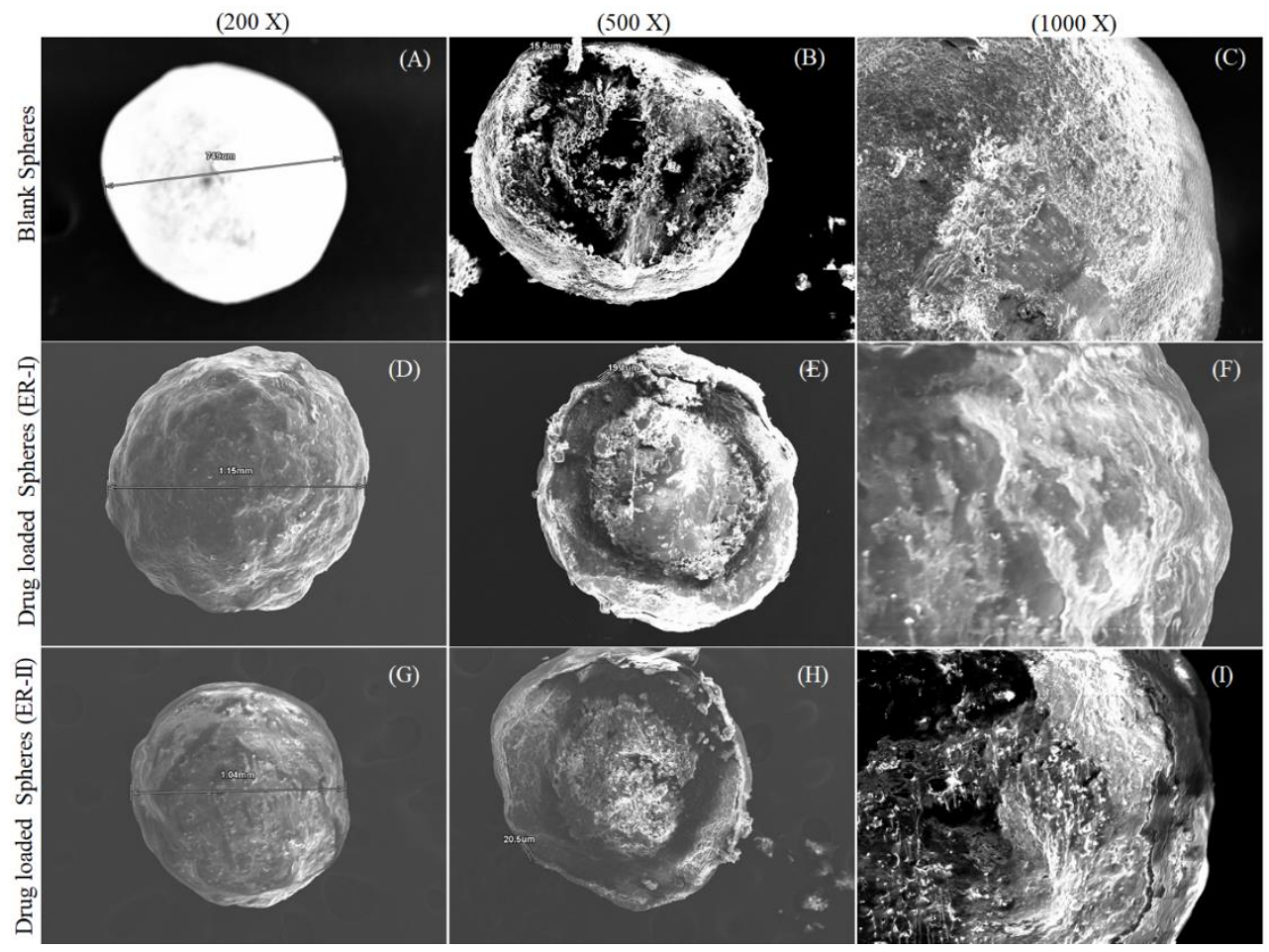

Figure 9. Scanning electron microscopic (SEM) photomicrographs of blank sugar spheres (A, B, C), drug loaded ER-I coated (formulation MUPS $\left.{ }_{13}\right)(\mathrm{D}, \mathrm{E}, \mathrm{F})$, and drug loaded ER-II coated (formulation MUPS 16 ) micro-pallets (G, H, I) at 200, 500, and $1000 \mathrm{~nm}$ scales, respectively.

The comparative dissolution study results suggested consistency in the release profiles from the capsules containing prepared MUPS (Figure 10). The drug release from the optimized formulation was identical to the innovator product in all the tested dissolution media. US-FDA suggests that if the value of similarity factor lies within 50-100, the two formulations have similar release profiles. If the value of dissimilarity factor $\left(f_{2}\right)$ is 0 and similarity factor $\left(f_{1}\right)$ is 100 then the two formulations are considered as identical with respect to their dissolution profiles [20]. In the present study, the dissimilarity factor $\left(f_{2}\right)$ values were less than 50 and similarity $\left(\mathrm{f}_{1}\right)$ factor values were greater than 50 in all tested dissolution media, indicating that the formulated MUPS and innovators product had similar release profiles (Table 2).
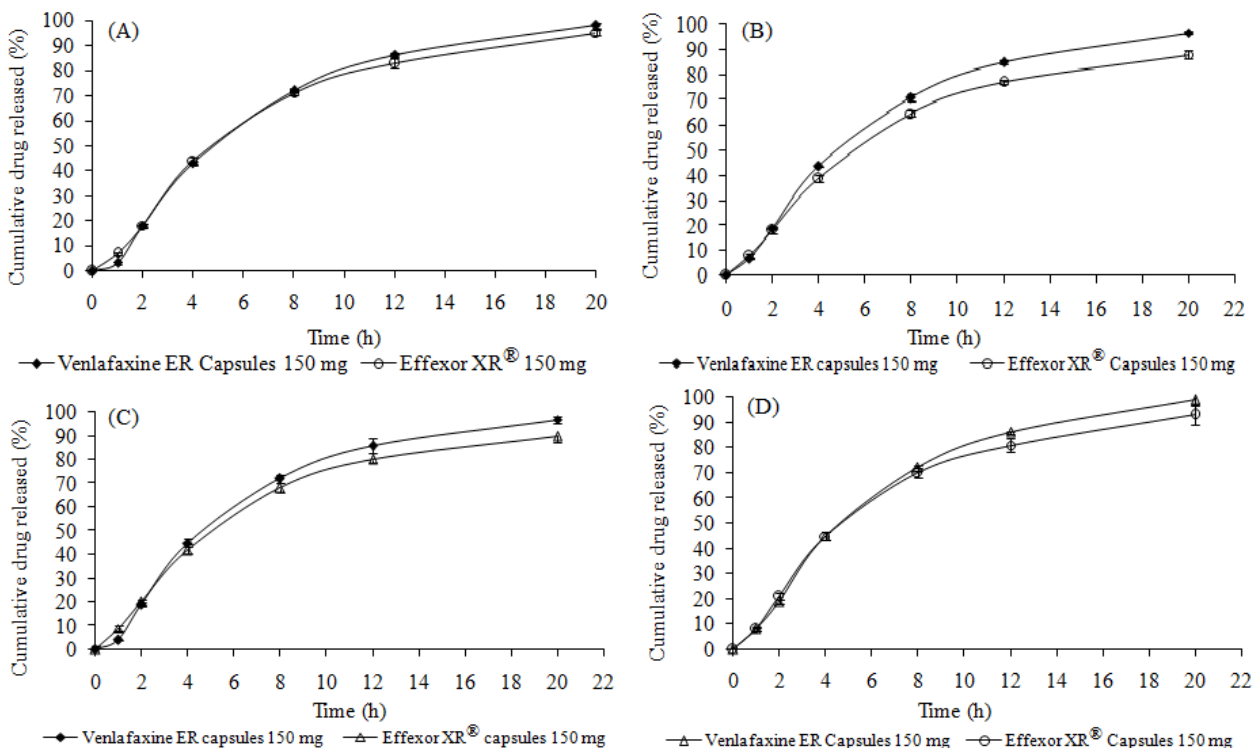

Figure 10. Results of comparative dissolution study of venlafaxine hydrochloride extended-release capsules containing MUPS (batch MUPS 1 ) coated with ER - I (10\%) and ER - II (11\%) and Effexor XR ${ }^{\circledR} 150 \mathrm{mg}$ in distilled water (A), $0.1 \mathrm{~N} \mathrm{HCl}(\mathrm{pH} 1.2)(\mathrm{B})$, acetate buffer ( $\mathrm{pH} 4.5)(\mathrm{C})$, and phosphate buffer (pH 6.8) (D). Data presents mean $\pm S D, n=6$. 
Table 2. Values of similarity factor $\left(f_{2}\right)$ and dissimilarity factor $\left(f_{1}\right)$ for the multimedia release profile of capsule containing MUPS (batch MUPS 1 ) coated with ER - I (10\%) and ER - II (11\%) and innovator product (Effexor $\mathrm{XR}^{\circledR}$, Wyeth Pharmaceuticals, USA).

\begin{tabular}{ccc}
\hline Dissolution media & $\begin{array}{c}\text { Similarity factor } \\
\left(\mathbf{f}_{\mathbf{2}}\right)\end{array}$ & Dissimilarity factor $\left(\mathbf{f}_{\mathbf{1}}\right)$ \\
\hline Water & 79 & 4 \\
$0.1 \mathrm{~N} \mathrm{HCl}$ & 61 & 9 \\
Acetate buffer, $\mathrm{pH} 4.5$ & 66 & 8 \\
Phosphate buffer, $\mathrm{pH}$ 6.8 & 73 & 5 \\
\hline
\end{tabular}

\section{CONCLUSION}

Venlafaxine hydrochloride loaded MUPS filled in hard gelatin capsule was produced by using polyvinyl pyrrolidone K-30, ethyl cellulose 20 cps and Hypromellose E 5LV. The influence of various binders, sphere size, viscosity grade of rate controlling polymer and coating ratios on the drug release profiles was systematically assessed. All these parameters had tremendous influence on the dissolution behavior of venlafaxine hydrochloride. Apart from the high percentage drug loading, binder showed prolonged drug release effect. The release profile of the best selected formulation matched with the marketed formulation (Effexor $\mathrm{XR}^{\circledR}$ ). Overall, the formulated venlafaxine hydrochloride loaded MUPS filled in hard gelatin capsule can open a new avenue for the delivery of therapeutics with improved potential.

\section{MATERIAL AND METHODS}

\subsection{Materials}

Venlafaxine hydrochloride was purchased from Amoli Organics Pvt. Ltd., Vadodara, India. Sugar spheres USNF (Pharma - spheres ${ }^{\mathrm{TM}}$ pellets neutral, 710-850 $\mu \mathrm{m}$ ) were obtained from Wilhelm Werner GmbH, Leverkusen, Germany. Hypromellose USP (Methocel E5LV premium) and Ethyl cellulose USNF were purchased from Colorcon, Goa, India. Polyvinyl pyrrolidone K-30 was received from BASF Ludwigshafen, Germany, India. Talc USP was obtained as a generous gift sample from Luzenac Val Chisone S.P.A., Torino, Italy. Empty hard gelatin capsule shell (Size ' 0 ' and ' 1 ') were procured from Associated Capsules Pvt. Ltd., India. All other chemicals used were of analytical grade.

\subsection{Methods}

\subsubsection{Preliminary trials to select formulation and process parameters}

Determination of polymorphism by $X$ - ray diffraction study: To study the effect of processing parameters on the physical state of drug (i.e., crystalline of amorphous), X-ray diffraction study of venlafaxine hydrochloride standard, venlafaxine hydrochloride API, venlafaxine hydrochloride extended-release particles (initial and stored at $40 \pm 2^{\circ} \mathrm{C} / 75 \pm 5 \% \mathrm{RH}$ for 3 months) filled in hard gelatin capsules was carried out using Xray powder diffractometer (D8 Advance Davinci, Bruker, Germany) [21].

Analysis of thermal behavior: The DSC thermograms of pure venlafaxine hydrochloride, and drug loaded extended-release particles (ER-I and ER-II) were recorded using a differential scanning calorimeter (DSC 8000, PerkinElmer, Inc, Massachusetts, United States). The instrument was calibrated using zinc $\left(419.5^{\circ} \mathrm{C}\right)$, tin $(232$ $\left.{ }^{\circ} \mathrm{C}\right)$, and indium $\left(156^{\circ} \mathrm{C}\right)$, as internal standards. The samples were accurately weighed $(5 \mathrm{mg})$ and sealed into an aluminum pan. The probes were heated from 5 to $390^{\circ} \mathrm{C}$ at a rate of $10 \mathrm{~K} / \mathrm{min}$ under nitrogen atmosphere.

Selection of inert carrier (sugar spheres): The size of sugar spheres can influence the rate of drug release. Hence, it was decided to study the particle size distribution of spheres in Effexor $\mathrm{XR}^{\circledR}$ capsules (Wyeth Pharmaceuticals, USA). Spheres were separated into different fractions using an electromagnetic sieve shaker (EMS-8, Electrolab Pvt. Ltd., Mumbai, India). The British Standard Sieves \# 14, \# 16, \# 18, \# 20 and \# 25 were arranged in ascending order i.e., from sieve no. The nest of sieves was shaken for 15 min (at 1.5 amplitude). Percentage cumulative retains was calculated for all the fractions.

Selection of binder and drug loading: Binder type has a significant effect on drug release profile from a pharmaceutical dosage form [22]. In the present study, we evaluated the effect of two different binders i.e., Hypromellose E 5LV and polyvinyl pyrrolidone K-30 for their binding efficiency (Table 3). Briefly, an accurately weighed quantity of venlafaxine hydrochloride was dissolved into the required quantity of purified water ( $60 \%$ of total quantity) in a suitable vessel to get a clear solution. Accurately weighed quantity of binders 
were added separately to the remaining quantity of purified water (i.e., $40 \%$ of total quantity) with continuous stirring to form a clear solution without foaming and any lump formation. Drug solution was added to the binder solution under continuous stirring. The resulting solution was passed through $250 \mu \mathrm{m}$ sieve (ASTM mesh \# 60) to remove the undissolved particles, if any. Required quantity of talc was added with continuous stirring to form a clear suspension of $45 \% \mathrm{w} / \mathrm{w}$ solid. The resulting drug suspension was sprayed over the sugar spheres. The actual quantity of venlafaxine hydrochloride was calculated based on actual assay and loss on drying (LOD) using following equation 1 where 313.86 and 277.40 are the molecular weights of Venlafaxine hydrochloride and Venlafaxine, respectively.

Quantity required $(\mathrm{mg} /$ capsule $)=$ Label claim $\times 313.86 / 277.40 \times 100 /(\% \mathrm{w} / \mathrm{w}$ assay on dried basis $) \times 100 /$

$$
(100-\% \mathrm{w} / \mathrm{w} \mathrm{LOD}) \text {. }
$$

Table 3. Composition of drug loaded spheres for screening of binder type in the formulation of extendedrelease venlafaxine hydrochloride particulate system.

\begin{tabular}{lll}
\hline Ingredients (mg/unit) & \multicolumn{2}{c}{ Formulation code } \\
\cline { 2 - 3 } & MUPS $_{1}$ & MUPS $_{2}$ \\
\hline Venlafaxine hydrochloride* & 169.715 & 169.715 \\
Sugar spheres & 174.285 & 174.285 \\
Hypromellose E 5LV & 16.000 & - \\
Polyvinyl pyrrolidone K-30 & - & 16.000 \\
Talc USP & 42.000 & 42.000 \\
Purified water & q.s & q.s \\
Total & 402.000 & 402.000 \\
\hline *equivalent to 150 mg of venlafaxine & &
\end{tabular}

Selection of viscosity grade of rate controlling polymer: As per the developmental plan, the drug loaded sugar spheres were coated with different viscosity grades of rate controlling polymer (ethyl cellulose) to examine the effect on dissolution profile at a level of $12 \%$ weight gain (Table 4 ). Briefly, required quantities of methanol and methylene chloride in the ratio of 40: 60 were transferred into a suitable vessel. Different viscosity grades of ethyl cellulose $(10 \mathrm{cps}$ and $20 \mathrm{cps}$ ) were added separately to the organic phase under continuous stirring to dissolve completely without formation of lumps. The resulting solution was passed through $250 \mu \mathrm{m}$ sieve (ASTM mesh \# 60) and sprayed over drug loaded spheres prepared using Hypromellose E 5LV. The final weight of the coated drug loaded sugar spheres was maintained at $450 \mathrm{mg}$.

\subsubsection{Preliminary trials to select formulation and process parameters}

To achieve the dissolution profile comparable to that of innovator product (Effexor $\mathrm{XR}{ }^{\circledR} 150 \mathrm{mg}$, Wyeth Pharmaceuticals, USA), it was decided to use Hypromellose E 5 LV as a channeling agent along with the rate controlling polymer (ethyl cellulose $20 \mathrm{cps}$ ) (Table 5). Initially for extended-release coating, Talc was not used in $\mathrm{MUPS}_{3}$ and $\mathrm{MUPS}_{4}$ trials. During the extended-release coating process charge development was observed and pellets were found to have tendency to adhere to the walls of the Wurster chamber (GFB Pro 30, M/s. Glatt, India). Hence to improve this behavior, talc was added in all the subsequent trials of extended-release coating. Talc was used as anti-tacking agent in drug loading and extended-release coating. Drug loading and extended-release coating were carried out as per the procedure described in section 4.2.1. Extended-release coating was applied to the drug loaded sugar spheres (formulation MUPS 1 ).

\subsubsection{Preliminary trials to select formulation and process parameters}

Optimization of binder concentration in drug loading: Based on the results of preliminary batches, three levels of Hypromellose E 5LV (4\%, 7\% and 10\%) (Table 6) were further used to study the percentage yield and drug loading efficiency. The procedure used to prepare drug loaded spheres was similar as mentioned under selection of binder and drug loading. 
Table 4. Screening of rate controlling coating polymer in the formulation of extended-release venlafaxine hydrochloride particulate system $\left(\mathrm{MUPS}_{1}\right)$.

\begin{tabular}{lll}
\hline \multirow{2}{*}{ Ingredients (mg/unit) } & \multicolumn{2}{c}{ Formulation code } \\
\cline { 2 - 3 } & MUPS $_{3}$ & MUPS $_{\mathbf{4}}$ \\
\hline Ethyl cellulose $10 \mathrm{cps}$ & 48.000 & - \\
Ethyl cellulose $20 \mathrm{cps}$ & - & 48.000 \\
Methanol & q.s. & q.s. \\
Methylene chloride & q.s. & q.s. \\
\hline
\end{tabular}

Table 5. Composition of extended-release coating applied to the drug loaded sugar spheres (formulation MUPS $_{1}$ ).

\begin{tabular}{lllll}
\hline Ingredients (mg/unit) & \multicolumn{4}{c}{ Formulation code } \\
\cline { 2 - 5 } & MUPS $_{\mathbf{5}}$ & MUPS $_{\mathbf{6}}$ & MUPS $_{\mathbf{7}}$ & MUPS $_{\mathbf{8}}$ \\
\hline Percentage coating & $10 \%$ & $10 \%$ & $10 \%$ & $10.5 \%$ \\
Ethyl cellulose 20 cps: Hypromellose E 5LV & $75: 25$ & $80: 20$ & $85: 15$ & $90: 10$ \\
Ethyl cellulose 20 cps & 27.30 & 29.10 & 30.94 & 29.59 \\
Hypromellose E 5LV & 9.20 & 7.30 & 5.46 & 3.44 \\
Talc USP & 3.60 & 3.60 & 3.60 & 8.97 \\
Methanol & q.s. & q.s. & q.s. & q.s. \\
Methylene chloride & q.s. & q.s. & q.s. & q.s. \\
Total weight of the coated MUPS $_{1}$ & 442.00 & 442.00 & 442.00 & 444.00 \\
\hline
\end{tabular}

Table 6. Composition for the optimization of level of selected binder in venlafaxine hydrochloride extendedrelease multiple unit particulate system.

\begin{tabular}{llll}
\hline Ingredients (mg/unit) & \multicolumn{3}{c}{ Formulation code } \\
\cline { 2 - 4 } & MUPS $_{\mathbf{9}}$ & MUPS $_{\mathbf{1 0}}$ & MUPS $_{\mathbf{1 1}}$ \\
\hline Venlafaxine hydrochloride* $^{*}$ & 169.715 & 169.715 & 169.715 \\
Sugar spheres (20/25) & 174.285 & 174.285 & 174.285 \\
Hypromellose E 5LV & $9.100(4 \%)$ & $16.000(7 \%)$ & $22.770(10 \%)$ \\
Talc USP & 48.900 & 42.000 & 35.230 \\
Purified water & q.s & q.s & q.s. \\
Total & 402.000 & 402.000 & 402.000 \\
\hline *equivalent to 150 mg of venlafaxine & &
\end{tabular}

Optimization of extended-release coating (ER - I and ER - II): To optimize the percentage buildup of extended-release coating, spheres were prepared with 7, 10 and $13 \%$ buildup using Ethyl cellulose $20 \mathrm{cps}$ and Hypromellose E 5LV at 80: 20 (ER - I). Similarly, three batches were prepared with 8, 11 and $14 \%$ buildup using Ethyl cellulose $20 \mathrm{cps}$ and Hypromellose E 5LV at 90: 10 (ER - II) (Table 7). The procedure used to prepare drug loaded spheres was similar as mentioned in section 4.2.1. Dissolution study was carried out in $900 \mathrm{~mL}$ of distilled water using USP tablet dissolution type I (TDT 08L, Electrolab, Mumbai, India). The temperature was maintained at $37^{\circ} \mathrm{C}$ and the basket was rotated at $100 \mathrm{rpm}$. Samples were withdrawn at predetermined time interval of 1, 2, 4, 6, 8, 10 and $12 \mathrm{~h}$ for ER - I and 1, 2, 4, 8, 12 and $20 \mathrm{~h}$ for ER - II. Same volume of dissolution media (maintained at $37^{\circ} \mathrm{C}$ ) was added after each sampling to maintain sink condition. Sampling was carried out in six replicated for each time point. The samples were analyzed using UV spectrophotometer (UV $3000^{+}$, Lab India Instruments, Mumbai, India) at $225 \mathrm{~nm}$ to estimate the cumulative percentage of drug released.

Optimization of blending ratio of ER - I and ER - II: Three different blending ratios (50:50, 60:40 and 70:30) of ER - I (10\% coated) and ER - II (11\% coated) were used to select best coating to achieve desired release profile of venlafaxine hydrochloride. Talc USP was used as a lubricant for the blending of the ERI and ER - II spheres (Table 8).

Morphological characterization of sugar based blank, and drug loaded ER coated MUPS: The morphological characterization of blank and drug loaded coated MUPS was carried out using a scanning electron microscope (SEM) (SU1510, Hitachi, Marunouchi, Japan). The samples for SEM analysis were attached on the stubs by 
adhesive carbon tape and coated with silver under argon atmosphere using a high-vacuum evaporator before observation. Coated samples were scanned, and photomicrographs were taken.

Table 7. Selection of extended-release coating (ER - I and ER - II) for venlafaxine hydrochloride extendedrelease multiple unit particulate system (formulation $\mathrm{MUPS}_{1}$ ).

\begin{tabular}{lllllll}
\hline Ingredients (mg/unit) & \multicolumn{3}{c}{ ER - I } & \multicolumn{3}{c}{ ER - II } \\
\cline { 2 - 7 } & MUPS $_{12}$ & MUPS $_{13}$ & MUPS $_{14}$ & MUPS $_{15}$ & MUPS $_{16}$ & MUPS $_{17}$ \\
\hline Extended-release coating & $7 \%$ & $10 \%$ & $13 \%$ & $8 \%$ & $11 \%$ & $14 \%$ \\
Ethyl cellulose USNF (20 cps) & 20.400 & 29.100 & 37.830 & 22.500 & 31.000 & 39.500 \\
Hypromellose E5LV & 5.200 & 7.300 & 9.490 & 2.600 & 3.600 & 4.600 \\
Talc USP & 2.400 & 3.60 & 4.680 & 6.800 & 9.400 & 11.820 \\
Methyl alcohol USNF & q.s. & q.s. & q.s. & q.s. & q.s. & q.s. \\
Methylene chloride USNF & q.s. & q.s. & q.s. & q.s & q.s. & q.s. \\
Total weight of the coated MUPS & 430.000 & 442.000 & 454.000 & 434.000 & 446.000 & 458.000
\end{tabular}

Table 8. Optimization of blending ratio of extended-release coatings (ER - I and ER - II).

\begin{tabular}{cccc}
\hline Ingredients (mg/capsule) & MUPS $_{18}$ & MUPS $_{19}$ & MUPS $_{20}$ \\
\hline Blending ratio (ER I: ER II) & $50: 50$ & $60: 40$ & $70: 30$ \\
ER - I spheres (10\% coated) & 223.58 & 268.30 & 313.00 \\
ER - II spheres (11\% coated) & 229.12 & 183.30 & 137.47 \\
Talc USP & 1.13 & 1.13 & 1.13 \\
Weight of blended spheres* & 453.58 & 452.73 & 451.6
\end{tabular}

The weights of ER-I and ER-II spheres are based on assay value of respective coated spheres, ${ }^{*}$ weight of the coated MUPS $_{1}$

\subsection{Optimized method for preparation of extended-release system}

\subsubsection{Drug loading}

For drug loading, weighed quantity of venlafaxine hydrochloride was dissolved in required quantity of purified water (60\% of total quantity) to get a clear solution. Hypromellose E 5LV was dissolved in the remaining quantity of purified water ( $40 \%$ of total quantity). Both the solutions were mixed under continuous stirring to form a clear solution without any lump formation and foaming. The resultant solution was passed through $250 \mu \mathrm{m}$ sieve (ASTM mesh \#60). Talc was added with continuous stirring to form a clear suspension of $45 \% \mathrm{w} / \mathrm{w}$ solids. The sugar spheres were sifted through $850 \mu \mathrm{m}$ sieve (ASTM mesh no \# 20). The under sized sugar spheres were passed through $710 \mu \mathrm{m}$ sieve (ASTM mesh no \# 25). The under-size spheres were discarded, and the required quantity of oversize spheres was loaded into Wurster chamber (GFB Pro 30, M/s. Glatt, India). The bed temperature was maintained at $35^{\circ} \mathrm{C} \pm 10^{\circ} \mathrm{C}$. The drug suspension containing talc was sprayed to achieve desired weight gain. The dried drug coated spheres were passed through $1.18 \mu \mathrm{m}$ sieve (ASTM mesh no \# 16).

\subsubsection{Extended-release coating}

The drug loaded spheres were used for ER - I (ethyl cellulose 20 cps and Hypromellose E 5LV at 80: 20) coating or ER - II (ethyl cellulose 20 cps $10 \%$ and Hypromellose E 5LV at 90: 10) coating. To prepare coating solutions, required quantity of ethyl cellulose and Hypromellose E 5LV were dissolved in a methanol and methylene chloride solvent system (40:60 ratio). The solutions were passed through $250 \mu \mathrm{m}$ sieve (ASTM mesh \#60). Talc was added under stirring to form uniform suspension of $6.53 \% \mathrm{w} / \mathrm{w}$ and $7.54 \% \mathrm{w} / \mathrm{w}$ solids, respectively for ER - I and ER - II coating. The coating of the spheres was carried out in a Wurster chamber (GFB Pro $30, \mathrm{M} / \mathrm{s}$. Glatt, India) at $37^{\circ} \mathrm{C} \pm 5^{\circ} \mathrm{C}$. The percentage of coating was $10 \%$ and $11 \%$, respectively for ER - I and ER - II coating. The coated spheres were dried to obtain the LOD as NMT 3.0\%. The dried coated 
spheres were sifted through $1.4 \mu \mathrm{m}$ sieve (ASTM mesh no \# 14). Oversized spheres were removed, and undersize spheres further passes through $710 \mu \mathrm{m}$ sieve (ASTM mesh no \# 25).

\subsubsection{Blending of ER - I and ER - II}

The ER I and ER II coated spheres were blended in the ratio of $60 \%$ (ER - I spheres) and $40 \%$ (ER - II spheres) for $10 \mathrm{~min}$. Talc was shifted through $150 \mu \mathrm{m}$ sieve (ASTM mesh no \# 100) and mixed to the ER - I and ER - II blend.

\subsubsection{Filling in hard gelatin capsule}

The blended/lubricated extended-release drug coated spheres were filled in empty hard gelatin capsules (size 0).

\subsection{Comparative multimedia dissolution study}

Being an extended-release product, a comparative dissolution data was generated with the optimized composition across the physiological $\mathrm{pH}(\mathrm{pH} 1.2$ to $\mathrm{pH}$ 6.8). This is done to ensure that the proposed formulation has similar release behavior in comparison to the innovator product across the physiological $\mathrm{pH}$. The comparative dissolution study of formulated extended release MUPS of venlafaxine hydrochloride filled in hard gelatin capsule (Size 0, No. 1) and innovator product (Effexor XR ${ }^{\circledR} 150$ mg, Wyeth Pharmaceuticals, USA) was carried out in $900 \mathrm{~mL}$ of different dissolution media (distilled water, $0.1 \mathrm{~N} \mathrm{HCl}$, acetate buffer ( $\mathrm{pH}$ 4.5) and phosphate buffer ( $\mathrm{pH}$ 6.8) using type I dissolution apparatus (Basket) at $100 \mathrm{rpm}$. The temperature of dissolution media was maintained at $37 \pm 0.5^{\circ} \mathrm{C}$. Sampling was carried out in six replicates at predetermined time intervals. The same volume of fresh dissolution media (maintained at $37^{\circ} \mathrm{C}$ ) was replaced after each sampling to maintain the sink condition. The samples were analyzed at $225 \mathrm{~nm}$ using UV spectrophotometer (UV $3000^{+}$, Lab India Instruments, Mumbai, India).

The release data of extended release MUPS (formulation MUPS ${ }_{1}$ ) coated with ER-I (10\%) and ER-II (11\%) filled in hard gelatin capsule was analyzed for similarity factor $\left(f_{2}\right)$ and dissimilarity factor $\left(f_{1}\right)$ to find out the degree of closeness between the release profiles of different formulations.

Author contributions: Concept - I.B., R.A., G.T.K.; Design - R.A., G.T.K.; Supervision - R.A., G.T.K.; Resources - I.B.; Materials - I.B.; Data Collection and/or Processing - I.B.; Analysis and/or Interpretation - R.A., G.T.K.; Literature Search - I.B., R.A.; Writing - R.A..; Critical Reviews - I.B., R.A., G.T.K.

Conflict of interest statement: The authors declared no conflict of interest in the manuscript.

\section{REFERENCES}

[1] Awasthi R, Kulkarni GT, Ramana MV, Pinto TJA, Kikuchi IS, Ghisleni DDM, Braga MS, Bank PD, Dua K. Dual crosslinked pectin-alginate network as sustained release hydrophilic matrix for repaglinide. Int J Biol Macromol. 2017; 97: 721-732. [CrossRef]

[2] Bhatt P, Patel D, Patel A, Patel A, Nagarsheth A. Oral controlled release systems: current strategies and challenges. In: Misra A, Shahiwala A, editors. Novel drug delivery technologies. Singapore: Springer Nature; 2019, p. 73-120. [CrossRef]

[3] Wheless JW, Phelps SJ. A clinician's guide to oral extended-release drug delivery systems in epilepsy. J Pediatr Pharmacol Ther. 2018: 23(4): 277-292. [CrossRef]

[4] Hoffman A. Pharmacodynamic aspects of sustained release preparations. Adv Drug Deliv Rev. 1998; 33(3): 185-199. [CrossRef]

[5] Ranade VV. Drug delivery systems 5A. Oral drug delivery. J Clin Pharmacol. 1991; 31(1): 2-16. [CrossRef]

[6] Leucuta SE. Drug delivery systems with modified release for systemic and biophase bioavailability. Curr Clin Pharmacol. 2012; 7(4): 282-317. [CrossRef]

[7] Qiu Y. Lee PI. Rational design of oral modified-release drug delivery systems. In: Qiu Y, Chen Y, Zhang G, Yu L, Mantri RV, editor. Developing solid oral dosage forms; United States: Academic Press; 2017, p. 519-554. [CrossRef]

[8] Fu Y, Kao WJ. Drug release kinetics and transport mechanisms of non-degradable and degradable polymeric delivery systems. Expert Opin Drug Deliv. 2010; 7(4): 429-444. [CrossRef] 
[9] Al-Hashimi N, Begg N, Alany RG, Hassanin H, Elshaer A. Oral modified release multiple-unit particulate systems: Compressed pellets, microparticles and nanoparticles. Pharmaceutics. 2018; 10(4): 176. [CrossRef]

[10] Patel S, Patel N, Misra M, Joshi A. Controlled-release domperidone pellets compressed into fast disintegrating tablets forming a multiple-unit pellet system (MUPS). J Drug Deliv Sci Technol. 2018; 45: 220-229. [CrossRef]

[11] Abdul S, Chandewar AV, Jaiswal SB. A flexible technology for modified-release drugs: multiple-unit pellet system (MUPS). J Control Release. 2010; 147(1): 2-16. [CrossRef]

[12] Bhattacharya S, Kshirsagar R, Joshi M, Pandita S. Extended release formulation of venlafaxine hydrochloride. U.S. Patent 7,807,195, October 5, 2010.

[13] Sanghavi BJ, Wolfbeis OS, Hirsch T, Swami NS. Nanomaterial-based electrochemical sensing of neurological drugs and neurotransmitters. Microchimica Acta. 2015; 182(1-2): 1-41. [CrossRef]

[14] Sherman DM, Clark JC, Lamer JU, A Steven. White. Extended release formulation of venlafaxine hydrochloride. United States Patent US6419958B2. 18.07.2002.

[15] Magalhães P, Alves G, Llerena A, Falcão A. Venlafaxine pharmacokinetics focused on drug metabolism and potential biomarkers. Drug Metabol Drug Interact. 2014; 29(3): 129-141. [CrossRef]

[16] Ali KA, Han J, Lee YJ, inventors; Wyeth LLC, assignee. Crystalline polymorph of venlafaxine hydrochloride and methods for the preparation thereof. United States patent US 7,030,164. 2006 Apr 18.

[17] Roy S, Aitipamula S, Nangia A. Thermochemical analysis of venlafaxine hydrochloride polymorphs 1- 5. Cryst Growth Des. 2005; 5(6): 2268-2276. [CrossRef]

[18] Madan JR, Patil K, Awasthi R, Dua K. Formulation and evaluation of solid self-microemulsifying drug delivery system for azilsartan medoxomil. Int J Polym Mater. 2021; 70(2): 100-116. [CrossRef]

[19] Murdande SB, Pikal MJ, Shanker RM, Bogner RH. Aqueous solubility of crystalline and amorphous drugs: Challenges in measurement. Pharm Dev Technol. 2011; 16: 187-200. [CrossRef]

[20] Awasthi R, Kulkarni GT. Development of novel gastroretentive floating particulate drug delivery system of gliclazide. Curr Drug Deliv. 2012; 9(5): 437-451. [CrossRef]

[21] Rahman Z, Siddiqui A, Bykadi S, Khan MA. Determination of tacrolimus crystalline fraction in the commercial immediate release amorphous solid dispersion products by a standardized X-ray powder diffraction method with chemometrics. Int J Pharm. 2014; 475(1-2): 462-470. [CrossRef]

[22] Tan DCT, Chin WW, Tan EH, Hong S, Gu W, Gokhale R. Effect of binders on the release rates of direct molded verapamil tablets using twin-screw extruder in melt granulation. Int J Pharm. 2014; 463(1): 89-97. [CrossRef]

This is an open access article which is publicly available on our journal's website under Institutional Repository at http://dspace.marmara.edu.tr. 